\title{
7.3 Innovations as the basis for socio-economic trends formation in the digital economy
}

Today humanity is experiencing extremely rapid changes in innovation and the state of socio-economic systems. In such periods, the ability to control the direction of transformation processes begins to play a significant role. In the scientific literature, this direction is characterized by "trend" and "tendency". It is no coincidence that more and more attention is being drawn to such concepts in the economic literature.

Recently, the word "trend" is one of the most used terms, especially in publicistic literature. Ratings of the most relevant trends in socio-economic and sociocultural development are published annually. Each area of public life has its own top 5, 10, 20 , etc. - the hottest innovation trends at the current time.

There are significantly fewer scientific works that analyze the content and mechanisms of trend formation. In this regard, we should mention S. Atkinson's works (Atkinson, 2016). He studied the dynamics of global megatrends of socioeconomic development. A team of German scientists from the Institute for Future Studies (Horx, 2020) proposed approaches to classify various types of socioeconomic trends. C. Efrat (2014) analyzed the impact of the future state of systems,

The authors of the book "Megatrends of Tomorrow's World" (Klein et al., 2017) analyzed the dependence of the trends of the highest level on the processes of the formation of trends of the lower classes. M. Dufva (Dufva, 2020b) analyzed the patterns of the formation of trends at various levels.

At the same time, in the scientific literature on the problems of trends, little attention is paid to systemic views on the dynamics of the formation of trends; in particular, there is no analysis of the specifics of modern mega- and metatrends, which form the channel of the epoch-making trend of the phase transition to a new socio-economic formation.

This research presents a systematic analysis of the dynamics of the formation of socio-economic trends. Particular attention is paid to the analysis of the content of 
modern industrial revolutions and the role they play in the formation of the epochmaking trend of the phase transition to a new socio-economic formation.

Most researchers agree that in the first approximation, the concept of trend means a specific dynamic characteristic of the system's behavior. As soon as this characteristic is active, it characterizes the features of the process in time. To be precise, it represents the patterns (algorithm, program, and recurring characteristic periods) in the system's behavior and the change in its parameters, which is ultimately embodied in the development of the system.

The concept of a trend is associated primarily with such informational characteristics as direction, direction, and vector. However, the trend characterizes the informative parameters of changes in the state of the system and the dynamics of its energy. The trend of changing the state of the system is implemented along the trajectories on which the system seeks to function in its most effective modes for a given period and given socio-economic conditions.

The trends of socio-economic development differ in the sphere where the corresponding processes take place and in the scale of the impact on society and nature.

Scientists from the German Institute for Future Research (Zukunftsinstitut) proposed a classification of trends, depending on the areas of activity (measurements), which can conditionally be included in the sphere of influence of a particular trend.

First, one smooth line (straight or curved) cannot convey the nature of an event in the future. It always has a turbulent nature, including due to bifurcation transformations. Therefore, any trends can only approximately convey the specifics of the future state of systems. Secondly, as a rule, trends have a wave character, which causes the rise and fall of their conditional energy, that is, the forces of influence on the spheres of society in different periods. Sooner or later, any trend loses its potential and gives way to other trends. Thirdly, in the operation of trends, one can observe a specific spiral-like behavior as a rule. This means that after an inevitable extinction of their influence on society, they can eventually, relatively speaking, return in a new 
quality and new forms. As the authors of the study above note: "each trend has its counter-trend, which emits the power of the" retro"(Horx, 2020).

The primary reason for the formation of a megatrend can be various events or phenomena that arise in the sociocultural sphere (for example, an increase in the level of education or urbanization of the population), in economy (industrialization, informatization, economic crisis, etc.), in scientific research.

So far, there are no clear generally recognized formal signs of assigning specific trends to the category of "mega" or "meta". Some researchers use typically only one of the named terms, ignoring the other; some use them as synonymous words.

For a megatrend to become a metatrend, it must affect qualitative changes in a person's lifestyle (have a manifestation in the civilizational dimension) and begin to significantly influence a person's relationship with nature (electrification, automation trends, etc.).

The megatrend can be defined as a large-scale, long-term trend of social development, which causes a change in the qualitative parameters of socio-economic systems. S. Efrat details the concept of a megatrend, defining it as global stable macroeconomic forces of development that affect business, economy, society, cultures, and personal life, thereby determining our future world and its growing pace changes (Efrat, 2020). M. Esposito emphasizes the ability of megatrends to influence the future development of systems. It defines megatrends as the trajectories of largescale events that occur today but affect future changes in demographics, natural resource use, climate change or inequality (Bhasin, 2018).

Despite the different formulations, these definitions have standard definitional features. First, they assume the large-scale nature of the changes associated with the megatrend; secondly, they imply a comprehensive coverage of the spheres of public life.

Some authors even talk about a "sea" of trends (Klein et al., 2017). And this is not far from the truth. Any spheres of human activity have their own trends: scientific, economic, business (business), engineering, agricultural and others. And in each of them, there are sub-trends in narrower divisions. 
Different authors call their own "fives", "tens", "twenty," and other "twenty" critical trends of our time. They differ in content, form, scale and even the order of formation. To show the degree of diversification of modern trends, we will cite as examples just a few megatrends belonging to various fields of activity (Efrat, 2020; Mitchell, 2020). Consider an example when a megatrend is formed based on disruptive technologies. These include, in particular, the development of a personal computer, mobile phone, efficient solar panel or 3D printer.

If successful, innovations are deployed in pioneering basic industrial plants, and new products enter the market in the form of the first commercial prototypes of serial products. In the sociocultural environment, information about a new product begins to circulate (advertising, promotions, consumer reviews). This is how a megatrend is formed for adherence to new technology and innovation and (most often) to a new type of product associated with it.

The consequences of the megatrend as a primary wave are: sociocultural trend when new products find their supporters among the population and entrepreneurs; product trend - when consumers begin to switch to new types of products massively; business trend - when the use of new technologies for the production of a new kind of product turns into a profitable business platform.

As the scale of the megatrend increases, it begins to influence the relationship between humans and nature. Under the influence of the trend, qualitative changes occur in a person (in particular, his worldview, level of education, ethical principles and attitudes towards social change), which can be interpreted as civilizational transformations. In such a situation, we can say that this socio-economic trend has acquired signs of a metatrend.

The trends of individual products, born from a certain disruptive technology, like streams from a source, can, uniting with the trends of other products, gain the strength of megatrends, influencing various spheres of public life: the sociocultural environment, the economy, and business. The trends of electrification, motorization, telephony, radio, television broadcasting, computerization, the use of mobile phones, GPS, 3D printers and other social phenomena have gone this way. 
Metatrends are more significant than megatrends. They cover the relationship between man and nature and lead to civilizational transformations in society. These metatrends have been associated with the inventions of the steam engine and the internal combustion engine. Each of these events initiated changes in the use of basic types of natural resources, the average level of education of a person and his way of life. It was associated with the formation of a large number of other trends that we mentioned above. The same can be said about the formation of a number of metatrends in the 20th and 21 st centuries. These trends were associated with the development of aviation, the development of global communications (radio, television, telephone, Internet), mass computerization of the population, informatization of the economy, digitalization of information systems, the development of alternative energy sources, the development of 3D printers and other social phenomena.

To have some idea of the content of individual metatrends, we suggest that you familiarize yourself with some of the results of S. Atkinson's research on forecasting the socio-economic development of humanity (Atkinson, 2016).

Socio-economic trends - from not very noticeable trends in the development of individual products to large-scale mega- and metatrends have their characteristics that refer them as social phenomena.

The nature of the dynamics of the formation of socio-economic trends is complex. It can be assumed that metatrends are formed by the flows of megatrends, like the rivers that feed them (Dufva, 2020b). In particular, such a metatrend in innovations as the spread of additive technologies depends on developing many megatrends (computerization, digitalization, development of new materials, etc.).

At the same time, it should be noted that, once formed, the flow of the metatrend begins to influence the configuration of the megatrends that form it, dictating their requests to them. In particular, in the metatrend of the development of additive technologies, the needs of $3 \mathrm{D}$ printing begin to determine the requirements for the development of the necessary computer programs, the properties of new materials, 
digital platforms, and the like. At the same time, these indicated directions of socioeconomic progress in other spheres act as independent metatrends.

As Mikko Dufva observed: "Megatrends are influenced by metatrends that lag behind the megatrends" (Dufva, 2020a). There are periods in the history of humanity when socio-economic trends acquire the features of phase transitions to a new socioeconomic formation. Then all conditions of the person's environment change and radical changes occur in the essential foundations of the person himself. Such trends are called socio-economic revolutions.

Now humanity is experiencing a new epochal trend - a phase transition to the future socio-economic formation. Its peculiarity is that it develops in three industrial revolutions at once - the Third, Fourth and Fifth, which act as a kind of general metatrends.

Any revolution brings radical changes to society. The third, fourth, and fifth industrial revolutions (the industrial revolution, the industrial revolution, the industrial revolution), which humanity is now experiencing, promise to become the basis of the phase transition. They change all spheres of human civilization, including the means of production, institutions, lifestyle, basic needs and occupations, and many other attributes of life.

Without pretending to be a full-scale study of the topic touched upon, we will only consider the formation of socio-economic trends in the coming transition period.

Economic and business are the two critical spheres of society that ensure the production and consumption of products. Therefore, they entirely depend on the essential technologies for the production of material resources and energy.

The third industrial revolution is the phenomenon of a radical qualitative transformation of socio-economic systems, which is characterized by the following processes: the transition to renewable energy sources and raw materials, the massive introduction of additive technologies and networked production systems, a digital basis for recording and transferring information, the formation of horizontal production and consumer structures and corresponding to them solidary forms of economic relations. 
The fourth industrial revolution is the phenomenon of the introduction of cyberphysical systems into the production and consumption of products, in which fully automated networks (in particular, the Internet of Things) appear, capable of operating without direct human participation (Rifkin, 2015; Shahan, 2016; Melnyk et al, 2019). The fifth industrial revolution is a phenomenon of human adaptation to a cyberized environment, in which the personal basis of a person develops, including synergistic integration of human cognitive abilities and artificial intelligence and human biological nature and technical means.

This research was funded by a grant from the state budget of the Ukraine, "Fundamentals of the phase transition to the additive economy: from disruptive technologies to institutional sociologization of decisions" (No. 0121U109557). 